\title{
Platelet concentrate in bovine reproduction: effects on in vitro embryo production and after intrauterine administration in repeat breeder cows
}

Anna Lange-Consiglio ${ }^{1}$, Nadia Cazzaniga ${ }^{1}$, Rosangela Garlappi ${ }^{2}$, Chiara Spelta ${ }^{3}$, Claudia Pollera ${ }^{4}$, Claudia Perrini ${ }^{1}$ and Fausto Cremonesi ${ }^{1,5^{*}}$

\begin{abstract}
Background: A repeat breeder cow (RBC) can be defined as an animal that after 3 or more inseminations cannot get pregnant because of fertilization failure or early embryonic death. If no cause is identified precisely, inadequate uterine receptivity is responsible for implantation failures. Since a large number of identified molecular mediators, such as cytokines, growth factors and lipids have been postulated to be involved in early feto-maternal interaction, in this study a different approach to the treatment of RBC syndrome has been employed using a platelet concentrate (PC) that contains a significant amount of growth factors accumulated in its a-granules.
\end{abstract}

Methods: Three explorative studies were performed. Initially, PC was supplemented in the in vitro embryo culture medium to study its effect on embryo-development. After the pilot study, 4 RBCs were treated with intrauterine administration of PC to evaluate proliferative potential of endometrium by immunohistochemical expression of the antigen Ki-67. Lastly, the effect of intrauterine administration of PC at 48 hrs after artificial insemination in RBCs was evaluated.

Results: The in vitro results show that $5 \%$ of PC and $5 \%$ of fetal calf serum (FCS) increase the rate of blastocysts compared with the control containing $10 \%$ FCS only (43.04 \% vs $35.00 \%$ respectively). The immunohistochemical study shows more proliferating nuclei in the treated uterine horn compared to the control one. After intrauterine insemination in RBCs, the percentage of pregnant cows in the control group was $33.33 \%$ compared to $70 \%$ of the treated animals.

Conclusion: We suppose that when embryo descends in uterus could find a more appropriate environment for nesting and subsequent pregnancy.

Keywords: Repeat breeder cows, Embryos, Platelet concentrate, Intrauterine administration

\section{Background}

Unexplained infertility, the so called repeat breeder cow (RBC) syndrome, involves a heterogeneous group of sub-fertile cows, with no anatomical abnormalities and infections of the reproductive tracts, nor estrous cycle alterations. A repeat breeder is defined as a cow that fails to become pregnant after 3 or more inseminations

\footnotetext{
* Correspondence: fausto.cremonesi@unimi.it

${ }^{1}$ Large Animal Hospital, Reproduction Unit, Università degli Studi di Milano, Via dell'Università 6, 26900 Lodi, Italy

${ }^{5}$ Department of Veterinary Science for Animal Health, Production and Food Safety, Università degli Studi di Milano, 20133 Milan, Italy

Full list of author information is available at the end of the article
}

as a consequence of either fertilization failure or early embryonic death [1].

The etiology of RBC syndrome is multi-factorial and unclear. The normal uterine environment promotes normal embryonic development but subclinical disorders compromise the survival of the embryo resulting in RBC syndrome. The RBCs are characterized by early embryonic loss [2], that decreases the conception rates [3, 4]. In some cases, the transfer of non-RBC donated embryos into RBC surrogates increased RBC pregnancy rate, indicating that the lower conception rate of RBCs is determined at early stages of embryo development [3]. The problem could be the embryo but also the 
oviductal and/or uterine environment. Ferreira et al. [5] provided evidence that RBC syndrome is associated with oocyte quality and that this negative effect is enhanced during summer heat stress, but it is general opinion that the successful implantation requires also a complex sequence of signaling events that are crucial to the establishment of pregnancy. In human medicine there is a proportion of women with 'unexplained' infertility in whom pregnancies fail before they are clinically recognized. Koot et al. [6] underline that this infertility could occur as a result of a malfunction of the endometrial-embryo 'dialogue' after the early phases of implantation. Indeed, the uterus is responsible for twothirds of failures whilst the embryo for only one-third $[7,8]$. A large number of molecular mediators, under the influence of ovarian hormones, have been postulated to be involved in this early embryo-maternal interaction. These mediators embrace a large number of inter-related molecules including adhesion molecules, cytokines, growth factors, lipids and others $[9,10]$. Many treatments have been proposed for prevention of RBC syndrome at both herd and individual level. These include, for example, nutritional supplements and assisted reproductive techniques, such as in vitro embryo production and embryo transfer. Commonly, therapies in use include hormonal treatments with progestins, GnRH, exogenous gonadotrophins and prostaglandins [1]. However, in view of the embryomaternal interaction a different approach to the treatment of RBC syndrome could be found using platelet concentrate (PC). Platelets contain significant quantities of growth factors (accumulated in their $\alpha$-granules), chemokines and cytokines and also active metabolites [11], that act in a paracrine manner on different cell types like myocytes [12], mesenchymal stem cells of different sources [13], condrocytes [14, 15], osteoblasts [16], fibroblasts [17]. Moreover, several in vitro studies have shown a direct dose-response influence of many growth factors on cell migration, cell proliferation, and matrix synthesis [18-20]. Transforming growth factor $\beta 1$ (TGF- $\beta 1$ ) and TGF- $\beta 2$, platelet derived growth factors (PDGF-AA, PDGF-BB, PDGF-AB), insulin-like growth factor 1 (IGF-I), epidermal growth factor (EGF), vascular endothelial growth factor (VEGF), fibroblast growth factor (FGF) and hepatocyte growth factor (HGF) are very important for regeneration processes. Indeed, these growth factors act synergistically to increase the infiltration of neutrophils and macrophages, to promote angiogenesis, fibroplasia, matrix deposition and, ultimately, re-epithelialization, inducing the consequent tissue regeneration [21]. Lastly, it is known the anti-inflammatory property of $\mathrm{PC}$ by the presence of anti-inflammatory agents including HGF [22].

In this context, the uterine administration of PC may be useful in peri-implantation, or in the healing process of clinically silent endometrial injuries because many cytokines act as intermediary links in the materno-fetal relationship including decidualization (in the women), implantation, placentation, embryogenesis and fetal growth [23]. Moreover, since pro-inflammatory factor transcripts in bovine endometrial epithelial cells are elevated in case of subclinical or clinical endometritis [24], we hypothesized that an early administration of PC, after artificial insemination (AI) and before the descent of the blastocyst in the uterus, could improve the uterine microenvironment for embryo implantation and counteract eventual subclinical endometritis.

\section{Methods \\ Materials}

Chemicals were obtained from Sigma Chemical (Milan, Italy) and tissue culture plastic dishes from Euroclone (Milan, Italy) unless otherwise specified.

\section{Experimental Design}

This study was based on three experiments as summarized in Table 1. The first experiment was to evaluate the effect of PC on in vitro embryo production by replacing fetal calf serum (FCS) with PC to establish whether this product is able to support embryo development. The second experiment evaluated the endometrium immunohistochemically, after in vivo PC administration, using Ki-67 as a marker of cell proliferation. The third in vivo experiment evaluated embryo implantation and development in RBCs following intrauterine administration of $\mathrm{PC}$ at $48 \mathrm{~h}$ after artificial insemination (AI).

\section{Animals and repeat breeder syndrome diagnosis}

All procedures were performed according to approved animal care and use protocols of the institutional ethics committee and to good veterinary practice for animal welfare as to European directive 2010/63/UE. Moreover, written farmers' consent was obtained at the beginning of the study.

The study was performed between January and April to reduce the influence of climate (i.e. a hot and humid climate, heavy rain, heat stress). Indeed, in the Italian environment late winter is probably the most stable period, with a low rain rate and temperature between 0 and $10{ }^{\circ} \mathrm{C}$. A total of 64 animals Holstein Friesians in which pregnancy had not been achieved despite 3 or more inseminations were enrolled in this study. Ultrasound examination was performed in each cow to detect any reproductive pathology (like ovarian cysts, pyometra, abscess...) that would result in exclusion of cows from the experiment because not considered RBCs. For each cow, on the day of the estrus, cervical mucus was tested and samples of cervical mucus were collected aseptically by swab (Equi-Vet, Kruuse, Marslev, Denmark). Bacteriological examinations were performed as reported by Gani et al. [25]. 
Table 1 Experimental design

\begin{tabular}{|c|c|c|}
\hline Experiments & $N^{\circ}$ samples & Parameter evaluated \\
\hline 1 In vitro: effect of different amounts of PC on embryo development & 705 oocytes & $\begin{array}{l}\text { - Rate of embryos } \\
\text { - Total cell numbers per blastocyst }\end{array}$ \\
\hline $\begin{array}{l}2 \text { In vivo: evaluation of endometrial cell proliferation, after in vivo PC } \\
\text { administration }\end{array}$ & $4 \mathrm{RBCs}$ & $\begin{array}{l}\text { Microscopic nuclear count of cells } \\
\text { expressing Ki-67 }\end{array}$ \\
\hline $\begin{array}{l}3 \text { In vivo: embryo implantation and development after intrauterine } \\
\text { administration of PC }\end{array}$ & $\begin{array}{l}30 \text { Treated RBCs } 30 \text { Control } \\
\text { RBCs }\end{array}$ & Rate of pregnancy \\
\hline
\end{tabular}

The RBCs were $385 \pm 12.5$ days in milking, had a weekly milk production of $128.6 \pm 0.7 \mathrm{~kg}, 6.05 \pm 4.84$ previous inseminations (minimum of 3 and maximum of 23 inseminations per animal), and were on lactation number $2.7 \pm 0.2$.

\section{Preparation of Platelet Concentrate (PC)}

Blood was obtained from 8 donor cows, at the forty days in milking because in this period the circulating platelet counts is higher than other periods (data not shown), in good health, free from infection that had not received medication during the previous two months. The collection of blood and the preparation of PC, with the method of double centrifugation, were performed as reported by Lange-Consiglio et al. [26]. Briefly, after surgical scrub preparation of a few centimetres of skin around the subcutaneous mammary vein, $450 \mathrm{ml}$ of blood was collected in ad hoc Terumo blood bags (Terumo Srl, Rome, Italy) containing CPDA- 1 by using the 16 gauge needle provided with the bags. The bags were transported at $+4{ }^{\circ} \mathrm{C}$ to the laboratory within $2 \mathrm{hrs}$ of collection and immediately processed. All separation steps to produce PC were performed under a horizontal laminar flow hood in aseptic conditions. To prepare the PC, the blood was drawn into sterile Falcon tubes of $50 \mathrm{ml}$ each. The tubes were centrifuged at $100 \mathrm{xg}$ for $30 \mathrm{~min}$. This caused separation of the blood into three components: red blood cells at the lowest level, 'buffy coat' comprised in the middle layer, and platelet-rich plasma (PRP) in the upper layer. Afterward, the PRP was carefully aspirated and distributed in new $50 \mathrm{ml}$ tubes and centrifuged again at 1500xg for $10 \mathrm{~min}$ to obtain the platelet pellet and the poor platelet plasma (PPP) at the upper layer. Afterwards, two thirds of the volume of PPP was aspirated for later use and the pellet mixed in the residual PPP volume to allow for platelet count before the final dilution with PPP to obtain PC at a standard concentration of $1 \times 10^{9}$ platelet $/ \mathrm{ml}$. All platelet counts on peripheral blood, PRP and PC were performed by an automatic hematology analyser HeCo Vet SEAC (Florence, Italy).

At the end of the process, PC was pooled and prepared at a standard concentration of $1 \times 10^{9}$ platelet $/ \mathrm{ml}$. The total volume of PC was aliquoted into $10 \mathrm{ml}$ usage doses that were stored in syringes. To release platelet derived factors, three cycles of freezing at $-80{ }^{\circ} \mathrm{C}$ and thawing at $37^{\circ} \mathrm{C}$ were performed [27]. Syringes containing $\mathrm{PC}$ dose were kept frozen at $-20{ }^{\circ} \mathrm{C}$ until use. The same pool of PC obtained from donor cows was used in all experiments and in all animals in an heterologous way meaning that it was employed in cows different from donor cows.

For supplementation in in vitro cultured embryos, to prevent coagulation and clot formation, a fibrinogen free PC was prepared as reported by Mojica-Henshaw et al. [28]. Briefly, after thawing, pooled PC was centrifuged at $4000 \mathrm{~g}$ for $20 \mathrm{~min}$, and the supernatant was collected and was manufactured by adding calcium chloride $(20 \% \mathrm{w} / \mathrm{v})$ at a ratio of 1:100. After allowing the product to form a clot overnight at $4{ }^{\circ} \mathrm{C}$, the coagulated product was centrifuged at $4000 \mathrm{~g}$ for $20 \mathrm{~min}$, and the supernatant was collected to obtain fibrinogen free PC.

\section{Experiment 1: effect of PC on in vitro embryo production}

The in vitro embryo production consisted of 3 steps: in vitro maturation of oocytes (IVM), in vitro fertilization (IVF) and in vitro culture of embryo (IVC) performed on a monolayer of cumulus cells. These steps were carried out as reported by Lange-Consiglio et al. [29]. Briefly, cumulus-oocyte complexes (COCs) were collected from ovaries obtained from an abattoir by aspirating follicles $2-8 \mathrm{~mm}$ in diameter and washing them twice in preincubated $\left(38.5{ }^{\circ} \mathrm{C}, 5 \% \mathrm{CO}_{2}\right.$ in air) TCM 199-HEPES buffered culture medium supplemented with 10 \% FCS.

IVM was performed for 24 h in TCM 199 Earl's Salt medium supplemented with $10 \%$ FCS, $5 \mu \mathrm{g} / \mathrm{ml} \mathrm{LH}$ (Lutropin, Bioniche, Canada), $0.5 \mu \mathrm{g} / \mathrm{ml} \mathrm{FSH}$ (Folltropin, Bioniche, Canada), $0.2 \mathrm{mM}$ sodium pyruvate, $10 \mu \mathrm{g} / \mathrm{ml}$ gentamycin and $1 \mathrm{mg} / \mathrm{ml}$ estradiol $17 \beta$. Cultures were in $70 \mu \mathrm{l}$ droplets (up to 20 oocytes/droplet) of the medium under oil, at $38.5{ }^{\circ} \mathrm{C}$ in $5 \% \mathrm{CO}_{2}$.

IVF was performed in Tyrode's-albumin-lactate-pyruvate (TALP) medium containing $2 \mathrm{mM}$ penicillamine, $1 \mathrm{mM}$ hypotaurine, $250 \mathrm{mM}$ epinephrine and $20 \mu \mathrm{g} / \mathrm{ml}$ heparin. Frozen-thawed semen was prepared by Percoll gradient (Amersham Pharmacia Biotec, Upsala, Sweden). In a $15 \mathrm{ml}$ conic tube, $1 \mathrm{ml}$ Percoll $90 \%$ was added followed by $1 \mathrm{ml}$ Percoll $45 \%$. Semen was thawed at $37^{\circ} \mathrm{C}$ for $30 \mathrm{sec}$, placed on the top of the Percoll 
gradient and centrifuged for $30 \mathrm{~min}$ at $300 \mathrm{xg}$. After removal of the supernatant, $4 \mathrm{ml}$ TALP medium were added and the sample centrifuged again for $2 \mathrm{~min}$ at 200 $\mathrm{xg}$ to remove excess Percoll.

Semen $\left(10^{7}\right.$ spermatozoa/ml $)$ was co-incubated with matured oocytes for $18 \mathrm{~h}$ at $38.5{ }^{\circ} \mathrm{C}$ in $5 \% \mathrm{CO}_{2}$. At the end of gametes co-culture, the cumulus cells were completely removed and evaluation of segmentation was carried out from the first day of embryo culture (considering as day zero the day of insemination) when embryos were equally divided into three different embryo culture media: 1) standard embryo culture medium (TCM-199) with $10 \%$ of FCS; 2) standard medium supplemented with $5 \%$ FCS and $5 \%$ PC; 3) standard medium supplemented with $10 \%$ PC. The percentage of embryos developing to blastocyst stage was evaluated daily up to day 7 after fertilization. Some blastocysts, as reported in Table 2, were stained with Hoechst 33342 $(10 \mu \mathrm{g} / \mathrm{ml})$ for $10 \mathrm{~min}$, and total cell numbers were counted under an epifluorescence microscope to estimate embryo quality. Hoechst 33342 dye was excited at 353-365 nm while the emission wavelength was set at $460 \mathrm{~nm}$.

\section{Experiment 2: immunohistochemical analysis of endometrium after in vivo $\mathrm{PC}$ administration}

Four RBCs, belonging to the group previously described, culled by owner decision were used to test the effect of PC on endometrial cell proliferation. On the ninth day of diestrous stage, $10 \mathrm{ml}$ of $\mathrm{PC}$ were administered into uterine horn ipsy-lateral (two cows) or contra-lateral (two cows) to the corpus luteum, maintaining the opposite horn as a control. After PC administration, a Foley catheter was inserted in the control horn and the balloon was inflated to prevent passage of PC and create the control environment. Our previous study (data not shown) demonstrated that insertion of a Foley catheter for 3 days does not alter the normal histological appearance of endometrium. These cows were slaughtered 3 days after the treatment (on the twelfth day of diestrus stage) and the 4 uteri were evaluated macroscopically for

Table 2 Number of blastocysts at 7 days in three different culture media and total cell number per blastocysts

\begin{tabular}{llll}
\hline Medium & $\begin{array}{l}N^{\circ} \text { of blastocysts } \\
\text { at 7 days (\%) }\end{array}$ & $\begin{array}{l}\mathrm{N}^{\circ} \text { of } \\
\text { embryos } \\
\text { observed }\end{array}$ & $\begin{array}{l}\text { Total cell } \\
\text { numbers per } \\
\text { blastocyst }\end{array}$ \\
\hline CTR (10 \% FCS) & $84 / 240(35.00 \pm 1.72)^{\mathrm{a}}$ & 29 & $104.6 \pm 10.5^{\mathrm{a}}$ \\
FCS 5 \% + PC 5 \% & $99 / 230(43.04 \pm 1.42)^{\mathrm{b}}$ & 31 & $123.4 \pm 8.3^{\mathrm{b}}$ \\
PC 10 \% & $64 / 235(27.23 \pm 1.39)^{\mathrm{c}}$ & 34 & $98.7 \pm 6.4^{\mathrm{c}}$ \\
\hline
\end{tabular}

The number are expressed as mean \pm standard deviation (SD) Different small letters superscript $(a, b)$ in the same column indicate statistically different comparisons $(P<0.05)$ differences between the treated and the control horns. For each horn, samples of middle/cranial portion were collected in formalin solution and were examined immunohistochemically for expression of the nuclear antigen $\mathrm{Ki}-67$, a marker of cell proliferation, using the $\mathrm{ABC}$ peroxidase method as reported by Turner et al. [30]. Briefly, the tissue was fixed in $4 \%$ buffered formalin, dehydrated, and embedded in paraffin. Sections $4 \mu \mathrm{m}$ thick were mounted on aptes (3-aminopropyl triethoxy silane, Sigma) coated slides, dewaxed, and rehydrated. Sections were immunostained using the standard $A B C$ technique with the rabbit antihuman/horse polyclonal antibody to Ki-67 (Dako Italia, S.p.A., Milan. Italy) used at 1:50 dilution. Ki-67 antibody is directed against different epitopes of the proliferation-related antigen and can be used on fixed sections. Endogenous peroxidase activity was blocked using $3 \%$ hydrogen peroxide. Pretreatment with microwaving in sodium citrate buffer, pH 6, was used. Non-specific primary antibody binding was blocked using fetal calf serum at a dilution of 1:20 for the ABC Ki-67. The primary antibody was applied for $18 \mathrm{hrs}$ at $+4{ }^{\circ} \mathrm{C}$ and washed in buffered saline. An antirabbit biotinylated secondary antibody (Insight Biotechnology Limited, Wembley Middlesex, UK) was applied at 1:200 dilution for $30 \mathrm{~min}$ at room temperature, followed by washes and then by application of the horseradish peroxidase streptavidin complex (Dako) at 1:400 dilution for $30 \mathrm{~min}$. The anti-rabbit secondary antibody is an affinity-purified polyclonal antibody with wellcharacterized specificity for rabbit IgG. Colour development was with metal enhanced diaminobenzidine (DAB) (Pierce and Warriner Ltd, Chester, UK) applied for $15 \mathrm{~min}$. The slides were lightly counterstained with Mayer emallume. The sections were viewed under a photomicroscope Olympus BX51 and nuclear count was performed on each section, at the level of endometrial epithelial cells, as number of positive cells to detect the entity of cell proliferation. Three different sections per cow and 4 microscopy fields for each section were counted.

\section{Experiment 3: in vivo effectiveness of intrauterine administration of PC at $48 \mathrm{~h}$ after $\mathrm{Al}$ in RBCs}

This experiment was carried out in 2 farms, managed in a cubicle yard. Sixty RBCs were randomly allocated into two groups: "treated group" $(\mathrm{N}=30)$ that received intrauterine administration of PC 48 hrs after AI and "control group" $(\mathrm{N}=30)$, that received no treatment in addition to AI. Treated group were characterized by $6.0 \pm 5.19$ inseminations prior to the enrollment in the study while control cows showed $6.1 \pm 4.49$ inseminations.

Cows displaying estrus in either group were submitted for insemination. The semen from the same bull was 
used for insemination in each group, eliminating the "bull" effect in the results of fertility.

All the cows were blood sampled for progesterone assay at day 0 (day of insemination), and then 4 and 8 days after insemination (respectively T0, T4 and T8). At $48 \mathrm{hrs}$ after insemination, $10 \mathrm{ml}$ of $\mathrm{PC}$ at $1 \times 10^{9}$ platelet $/ \mathrm{ml}$ were administered into the uterus in the cows in the treated group. This time was supposed to be ideal after AI not to disturb spermatozoa progression and before the embryo reaches the uterus. Ten $\mathrm{ml}$ of PC were administrated following previous study (data not shown) in which this volume proved to be evenly distributed along the uterine horns without signs of excessive distension allowing to reach the deepest portion of the organ. Ultrasound examination for pregnancy diagnosis was performed in all cows 32 days after insemination and confirmed at 60 days.

\section{Bacteriological examination of cervical mucus}

Bacteriological investigations were performed to detect aerobic and anaerobic microorganisms, such as Trueperella pyogenes, Haemophylus sommni, Staphylococcus sp., Streptococcus sp., Enterobacteriaceae, Prevotella sp., Fusobacterium spp. Each sample was plated on blood agar (agar with $5 \%$ sheep blood, Sintak, Italy) for isolated colonies. The plates were incubated for $24-48 \mathrm{hrs}$ in aerobic and anaerobic conditions at $37^{\circ} \pm 2{ }^{\circ} \mathrm{C}$. Identification of bacteria was based on colonial morphology, Gram staining, and biochemical tests such as catalase, oxidase, coagulase according to the guidelines of the Bergey's manual of Systematic Bacteriology and the standard bacterial procedure of CLSI (Clinical and Laboratory Standards Institute) and confirmed by API-System (bioMerieux, France).

\section{Intrauterine administration of platelet concentrate}

After thawing and warming at $38{ }^{\circ} \mathrm{C}$, the syringes of PC were connected to a sterile disposable intrauterine cannula, so that samples could be delivered through the vestibule, the vagina and the cervix to reach deep into the uterine horn ipsi-lateral to the newly formed corpus luteum. Plastic catheters with atraumatic ends were used. Ten $\mathrm{ml}$ of PC were administrated to cows in the treatment group $48 \mathrm{hrs}$ after insemination.

\section{Progesterone assay}

Plasma samples were obtained by jugular venipuncture $(2-5 \mathrm{ml})$. Blood was collected in heparinized tubes and centrifuged at $1000 x g$ for $10 \mathrm{~min}$. The plasma concentration of progesterone was assessed using a quantitative automated method based on the enzyme-linked fluorescent assay (ELFA) technique (Mini-Vidas; bioMérieux Italia S.p.A., Florence, Italy.

\section{Statistical analysis}

The collection efficiency of platelets for each PC was analyzed using the following formulas [31]:

$$
\begin{aligned}
& \text { efficiency for platelet collection } \\
& =\frac{\text { platelet count } / \mu \mathrm{l} \text { in } \mathrm{PC} \mathrm{x} \text { volume of } \mathrm{PC}}{\text { platelet count in whole }} \\
& \text { blood } / \mu \mathrm{l} x \text { volume of whole blood }
\end{aligned}
$$

The statistical analysis of the data collected during the study, except for bacteriological data, was conducted using chi-square test. For all tests, differences were considered statistically significant when $P \leq 0.05$. The data were analyzed using the "Software GraphPad Instat 3.00 for Windows" (La Jolla, CA, USA).

\section{Results}

\section{Platelet collection efficiency and product sterility test}

The platelet collection efficiency for the PCs was $10.9 \pm$ $2.3 \%$, indicating that $10.9 \pm 2.3 \mathrm{ml}$ of PC at the concentration of $1 \times 10^{9}$ platelet $/ \mathrm{ml}$ were obtained from $100 \mathrm{ml}$ of blood.

The bacterial sterility test performed on the PC produced in the laboratory has always given negative results, confirming that the experimentation has been performed in accordance with the appropriate standards of laboratory sterility.

\section{Experiment 1: effect of PC on in vitro embryo production}

During three experiments, 168 ovaries were processed, 705 oocytes were collected, with an average of 4.2 oocytes collected per ovary. The results related to the culture of embryos in the standard medium (CTR) show that the rate of cleavage of three replicates is $66.80 \pm 2.07$.

Results related to embryo culture show that the rate of blastocyst development was statistically significant different $(P<0.001)$ among all the three media tested and the best embryo production rate and quality was achieved in the culture medium supplemented with $5 \%$ PC and $5 \%$ FCS (Table 2).

\section{Experiment 2: immunohistochemical analysis of endometrium after in vivo PC administration}

No macroscopic alterations were observed in any of the uterine samples. Immunohistochemical examination for the unmasking of the nuclear antigen Ki-67 showed that in all animals there were statistically more proliferating nuclei in the treated uterine horn compared to the control one (Table 3 and Fig. 1). 
Table 3 Microscopic nuclear count of cells expressing nuclear antigen Ki-67 protein in control (CTR) and treated (TRT) uterine horns of 4 cows in different sections and different microscopic fields

\begin{tabular}{|c|c|c|c|c|c|c|c|}
\hline \multicolumn{2}{|l|}{1} & \multicolumn{2}{|l|}{2} & \multicolumn{2}{|l|}{3} & \multicolumn{2}{|l|}{4} \\
\hline \multicolumn{2}{|c|}{ Uterine horn } & \multicolumn{2}{|c|}{ Uterine horn } & \multicolumn{2}{|c|}{ Uterine horn } & \multicolumn{2}{|c|}{ Uterine horn } \\
\hline CTR & TRT & CTR & TRT & CTR & TRT & CTR & TRT \\
\hline $2 \pm 0.7^{a}$ & $12 \pm 0.2^{b}$ & $1 \pm 0.2^{a}$ & $10 \pm 0.6^{b}$ & $5 \pm 2.9^{a}$ & $18 \pm 2.3^{b}$ & $14 \pm 3.8^{a}$ & $40 \pm 4.2^{b}$ \\
\hline
\end{tabular}

Legend: CTR Control; TRT Treated. The number are expressed as mean \pm standard deviation (SD)

Different small letters superscript $(a, b)$ in the same line indicate statistically different comparisons $(P<0.05)$

\section{Experiment 3: in vivo effectiveness of intrauterine administration of PC at 48 hrs after Al in RBCs}

The clinical aspect of the uterus in all animals during the clinical examination at the estrous stage appeared normal in size, without presence of drains and with adequate, clear and stringy estrous mucus.

Progesterone values did not differ from those expected in a normal estrous cycle. Indeed, these values were lower than $1 \mathrm{ng} / \mathrm{ml}$ during peri-estrus and then increased gradually at day +4 as a result of ovulation and further increased at day +8 post insemination (Table 4 ). The percentage of pregnant cows in the control group was of $33.33 \%(10 / 30)$ compared to $70 \%(21 / 30)$ of the treated animals. The difference in pregnancy rates between the treated group and the control group was statistically significant $(P<0.05 ;$ Table 4$)$. There was no correlation between treatment results and number of past inseminations before this study and characterizing the status of the enrolled RBCs $(P=0.62)$. All treated and control RBCs diagnosed as pregnant gave birth to normal offsprings.

\section{Microbiological results}

No significant bacterial growth was observed in any of the cervical mucus samples obtained from cows of both experimental groups. The microorganism Aerococcus viridans was isolate only from one cow.

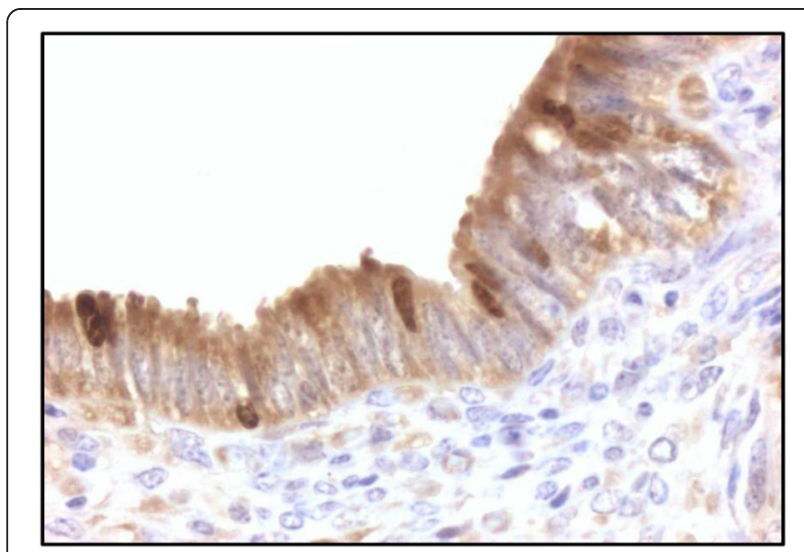

Fig. 1 Immunohystochemical analysis. Nuclear positivity to Ki-67 protein. Magnification 100x

\section{Discussion}

Studies in humans and in other mammals have shown that cytokines and growth factors are produced by the pre-implantation embryo and cells of the reproductive tract, even if the exact combinations required for successful implantation are not yet fully understood [23]. Based on the current knowledge of the regenerative effect of PC due to its high growth factor and cytokine content [22], this study proposes a novel therapeutic approach. Autologous PC is known to accelerate the healing process in human medicine, and has been used in maxillofacial surgery, muscle and/or tendon repair, and reversal of skin ulcers [21]. In veterinary medicine there are few clinical reports of the use of PC. It has been mainly used for promoting equine tendon repair [32], but there are some reports of its use in intestinal wound healing in pigs [33], in a large cutaneous lesion in a dog [34] and in bovine mastitis in which it was used in heterologous way [26]. In all cases PC or platelet rich plasma showed a clear regenerative potential.

For this reason, in this preliminary investigation, we performed three explorative studies in vitro and in vivo. Only one paper [35] described the effects of platelet rich plasma on morula and blastocysts in vitro production. In our study and in our experimental conditions (i.e. platelet concentration at $1 \mathrm{x} 10^{9} / \mathrm{ml}$ ), at first we studied the effect of PC on in vitro embryo development using two different percentages (respectively $5 \%$ and $10 \%$ ) of PC as a partial or complete replacement of FCS. The rate of blastocyst production and the total cells number of the blastocysts were statistically increased in the medium with $5 \%$ PC and $5 \%$ FCS when compared to both the control and medium with $10 \%$ PC. Platelets release many growth factors, including FGF, TGF-6, PDGF and EGF $[36,37]$ that can stimulate bovine embryo development [38, 39]. Indeed, Munson et al. [40] demonstrated that TGF-6 and PDGF act synergistically to promote proliferation of both bovine trophoblastic cells and endometrial epithelial cells during in vitro culture. Moreover, EGF in vivo is produced by endometrial cells and its receptors have been detected in the embryo itself, where EGF acts through the phosphorylation of membrane proteins as a mitogen, promoting DNA and RNA synthesis. As pregnancy progresses, the increased production of EGF enhances trophoblast differentiation [41], promoting cell attachment and embryo 
Table 4 Results of in vivo effectiveness of intrauterine administration of PC $48 \mathrm{~h}$ after $\mathrm{Al}$ in RBCs

\begin{tabular}{llllllll}
\hline & & \multicolumn{2}{l}{ Progesterone value $(\mathrm{ng} / \mathrm{ml})$} & & & \\
\cline { 2 - 5 } & No & T4 & T8 & & Pregnant (\%) & Not Pregnant (\%) & Delivery (\%) \\
\hline Control & 30 & $0.40 \pm 0.21^{\mathrm{a}}$ & $2.63 \pm 0.96^{\mathrm{a}}$ & $7.75 \pm 2.21^{\mathrm{a}}$ & $10(33.33)^{\mathrm{a}}$ & $20(66.67)^{\mathrm{a}}$ & $10(100)$ \\
Treated & 30 & $0.40 \pm 0.17^{\mathrm{a}}$ & $3.12 \pm 0.85^{\mathrm{a}}$ & $8.33 \pm 2.14^{\mathrm{a}}$ & $21(70.00)^{\mathrm{b}}$ & $9(30.00)^{\mathrm{b}}$ & $21(100)$ \\
\hline
\end{tabular}

Different small letters superscript $(a, b)$ in the same column indicate statistically different comparisons $(P<0.05)$

development [23]. Fibronectin and other glycoproteins are also released from platelets after aggregation, and Larson et al. [42] discovered that a serum-free medium supplemented with fibronectin provides the extracellular matrix required by the embryo to develop to the blastocyst stage during in vitro culture. In a speculative interpretation, the embryo culture systems supplemented with PC may have provided TGF-6, PDGF and the matrix of extracellular fibronectin necessary to support the development of embryo during in vitro culture, thus replicating the uterine microenvironment appropriate for embryo growth, viability, and for cytokine secretion [23]. It is possible that the low rate of embryos obtained in the medium with $10 \%$ PC, compared to control, results from an excess of factors that may have had an inhibitory effect on the embryo development.

This in vitro study provided a useful starting point for the pre-clinical investigation in order to use PC in in vivo trials. Immunohistochemical examination of uterine samples from animals slaughtered 3 days after PC treatment showed that there was more expression of the nuclear antigen Ki-67 in samples from treated uterine horns compared to the controls. Cell proliferation is not enough indicative for uterine health but Ki-67 is expressed in the nuclei of proliferating cells. In tissues with a high proliferative rate it is expressed in all cell cycle phases except for the resting or G0 phases [43, 44] and reaches a maximum level during G2 and M [45]. Since Ki-67 is significantly more expressed in samples from treated uterine horns, it may be supposed that the growth factors released by platelets in the PC may have an effect on endometrial cell proliferation.

After these preliminary studies, the in vivo administration of PC into the uterus of RBCs at 48 hrs after insemination was performed.

The gynecological clinical status and the progesterone analysis performed in this study ensured that pregnancy losses in enrolled animals were not caused by abnormal ovarian cycles, an important condition for classification of cows as RBC, as reported by Gustafsson et al. [46]. The progesterone analysis also allowed us to exclude hypoluteinism as a possible cause of repeat breeding. In fact, all animals showed progesterone values exceeding the $2 \mathrm{ng} / \mathrm{ml}$ threshold both at day +4 and +8 postinsemination [47]. Moreover, bacteriological examination performed on cervical mucus confirmed the absence of bacterial infections in the genital tract, as the only isolated microorganism was Aerococcus viridans, a bacterium not recognized as a uterine pathogen.

In the in vivo study, there were more pregnant cows in the treated group compared to the control group. This suggests that the in vivo intrauterine administration of PC $48 \mathrm{hrs}$ after insemination, time supposed to be ideal after AI not to disturb spermatozoa progression and before the embryo reaches the uterus, could make the uterine environment favorable to embryo implantation. This may be the effect of platelet growth factors on regeneration and/ or the healing of clinically silent endometrial abnormalities. Furthermore, PC should enrich the uterine environment with factors necessary for embryo development. Uterine glands produce a glycoprotein-rich secretion, which is believed to support the embryo during the pre-implantation period [48]. In addition to providing nutrition for the conceptus, this secretion contains a complex array of growth factors and cytokines. Katagiri and Takahashi [49] reported that RBCs show abnormalities in the growth factor-cytokine network - specifically in endometrial EGF concentrations. Cyclic cows have two peaks of EGF concentrations on days 2-4 and 13-14 of the oestrous cycle, but these peaks are lost or diminished in about $70 \%$ of RBCs [49]. The EGF family could act on the trophectoderm promoting cell attachment and embryo development [23]. Since PC contains EGF, treatments targeting the endometrial growth factor regulatory network may be an effective way to deal with RBCs when uterine problems limit the production of this or other growth factors.

\section{Conclusions}

The preliminary data regarding the administration of PC into the uterus of animals at $48 \mathrm{hrs}$ after insemination produced very encouraging results in RBCs. From our data, we hypothesize that PC, whose content is known, enriches the uterine environment with factors necessary for embryo development and counteracts eventual subclinical endometritis by its anti-inflammatory properties. The obtained results in our three different explorative studies are very interesting. This research could offer a new therapeutic strategy for RBC syndrome and also open the possibility for using PC in future embryotransfer programs in both human and veterinary medicine as a vehicle to transfer embryos at the time of transplantation, with the aim of improving the uterine environment for implantation. 


\section{Abbreviations}

Al: artificial insemination; EGF: Epidermal Growth Factor; FCS: Fetal Calf Serum; FGF: Fibroblast Growth Factor; HGF: Hepatocyte Growth Factor; IGF-I: Insulin-like Growth Factor 1; IVC: in vitro Culture of Embryo; IVF: in vitro Fertilization; IVM: in vitro Maturation; PC: Platelet Concentrate; PDGFAA: PDGF-BB, PDGF-AB, Platelet Derived Growth Factors; RBC: Repeat Breeder Cow; TGF- $\beta 1$ : Transforming Growth Factor $\beta 1$; TGF- $\beta 2$ : Transforming Growth Factor $\beta 2$; VEGF: Vascular Endothelial Growth Factor.

\section{Competing interests}

All authors declare that there is no financial or non-financial competing interest that could be perceived as prejudicing the impartiality of the reported research.

\section{Authors' contributions}

$\mathrm{ALC}$ is responsible for the study concept and participated in designing the study, performed the in vitro study, collected and interpreted data performing statistical analysis, wrote and reviewed the manuscript and approved the final version. NC performed the in vitro study, collected and interpreted data, wrote the manuscript and approved the final version. RG and CS performed the in vivo study, collected and interpreted data, and approved the final version. $\mathrm{CP}$ and $\mathrm{CP}$ took part in collecting and interpreting data and approved the final version. $\mathrm{FC}$ is responsible for the study concept and participated in designing the study, performed the in vivo study, collected and interpreted data, revised and approved the final version of manuscript.

\section{Acknowledgements}

We sincerely thank Dr Pietro Riccaboni and Dr Marco Rondena of the DIVET Department, Università degli Studi di Milano, for their assistance in immunohistochemical techniques.

\section{Author details}

'Large Animal Hospital, Reproduction Unit, Università degli Studi di Milano, Via dell'Università 6, 26900 Lodi, Italy. ${ }^{2}$ Private practitioner, 26833Merlino, Milan, Italy. ${ }^{3}$ Private practitioner, 27100 Pavia, Italy. ${ }^{4}$ Department of Veterinary Science and Public Health, Università degli Studi di Milano, 20133 Milan, Italy. ${ }^{5}$ Department of Veterinary Science for Animal Health, Production and Food Safety, Università degli Studi di Milano, 20133 Milan, Italy.

Received: 20 April 2015 Accepted: 9 June 2015

Published online: 19 June 2015

\section{References}

1. Perez-Marin CC, Molina Moreno L, Vizuete CG. Clinical approach to the repeat breeder cow syndrome. A Bird's-Eye View of Veterinary Medicine. 2011;18:337-62.

2. Gustafsson H, Larsson K. Embryonic mortality in heifers after artificial insemination and embryo transfer: differences between virgin and repeat breeder heifers. Res Vet Sci. 1985;39:271-4

3. Ferreira RM, Ayres H, Chiaratti MR, Rodrigues CA, Freitas BG, Meirelles FV, et al. Heat stress and embryo production in high-producing dairy cows. Acta Sci Vet. 2010;38:s277-315.

4. Yusuf M, Nakao T, Ranasinghe RB, Gautam G, Long ST, Yoshida C, et al. Reproductive performance of repeat breeders in dairy herds. Theriogenology. 2010;73:1220-9.

5. Ferreira RM, Ayres H, Chiaratti MR, Ferraz ML, Araújo AB, Rodrigues CA, et al. The low fertility of repeat-breeder cows during summer heat stress is related to a low oocyte competence to develop into blastocysts. J Dairy Sci. 2011:94:2383-92.

6. Koot YEM, Boomsma CM, Eijkemans MJC, Lentjes EGW, Macklon NS. Recurrent pre-clinical pregnancy loss is unlikely to be a 'cause' of unexplained infertility. Hum Reprod. 2011;26:2636-41.

7. Simon C, Moreno C, Remohi J, Pellicer A. Cytokines and embryo implantation. J Reprod Immunol. 1998:39:117-31.

8. Ledee-Bataille N, Lapree-Delage G, Taupin JL, Dubanchet S, Frydman R, Chaouat G. Concentration of leukaemia inhibitory factor (LIF) in uterine flushing fluid is highly predictive of embryo implantation. Hum Reprod. 2002;17:213-8.

9. Lessey BA, Damjanovich L, Coutifaris C, Castelbaum A, Albelda SM, Buck CA. Integrin adhesion molecules in the human endometrium. correlation with the normal and abnormal menstrual cycle. J Clin Invest. 1992;90:188-95.
10. Simon C, Martin JC, Pellicer A. Paracrine regulators of implantation. Baillière's Best Pract Res Clin Obstet Gynaecol. 2000;14:815-26.

11. Macaulay IC, Carr P, Gusnanto A, Ouwehand WH, Fitzgerald D, Watkins NA. Platelet genomics and proteomics in human health and disease. J Clin Invest. 2005;115:3370-7.

12. Mazzocca AD, McCarthy MB, Chowaniec DM, Dugdale EM, Hansen D, Cote MP, et al. The positive effects of different platelet-rich plasma methods on human muscle, bone, and tendon cells. Am J Sports Med. 2012:40:1742-9.

13. Cho HS, Song LH, Park SY, Sung MC, Ahn MW, Song KE. Individual variation in growth factor concentrations in platelet-rich plasma and its influence on human mesenchymal stem cells. Korean J Lab Med. 2011;31:212-8.

14. Drengk A, Zapf A, Stürmer EK, Stürmer KM, Frosch KH. Influence of platelet-rich plasma on chondrogenic differentiation and proliferation of chondrocytes and mesenchymal stem cells. Cells Tissues Organs. 2009;189:317-26.

15. Van Buul GM, Koevoet WL, Kops N, Bos PK, Verhaar JA, Weinans H, et al. Platelet-rich plasma releasate inhibits inflammatory processes in osteoarthritic chondrocytes. Am J Sports Med. 2011;39:2362-70.

16. Graziani F, Ivanovski S, Cei S, Ducci F, Tonetti M, Gabriele M. The in vitro effect of different concentrations on osteoblasts and fibroblasts. Clin Oral Implants Res. 2005;16:456-60.

17. Anitua E, Sánchez M, del Mar ZM, de la Fuente M, Prado R, Orive G, et al. Fibroblastic response to treatment with different preparations rich in growth factors. Cell Prolif. 2009;42:162-70.

18. Thomopoulos S, Harwood FL, Silva MJ, Amiel D, Gelberman RH. Effect of several growth factors on canine flexor tendon fibroblast proliferation and collagen synthesis in vitro. J Hand Surg. 2005;30:441-7.

19. Costa MA, Wu C, Pham BV, Chong AK, Pham H-M, Chang J. Tissue engineering of flexor tendons: optimization of tenocyte proliferation using growth factor supplementation. Tissue Eng. 2006;12:1937-43.

20. Haupt JL, Donnelly BP, Nixon AJ. Effects of platelet-derived growth factor-BB on the metabolic function and morphologic features of equine tendon in explant culture. Am J Vet Res. 2006;67:1595-600.

21. Anitua E, Andia I, Ardanza B, Nurden P, Nurden AT. Autologous platelets as a source of proteins for healing and tissue regeneration. Thromb Haemost. 2004;91:4-15.

22. Bendinelli P, Matteucci E, Dogliotti G, Corsi MM, Banfi G, Maroni P, et al. Molecular basis of anti-inflammatory action of platelet rich plasma on human chondrocytes: mechanisms of NF-kB inhibition via HGF. J Cell Physiol. 2010;225:757-66.

23. Castro-Rendón WA, Castro-Álvarez JF, Guzmán-Martinez C, Bueno-Sanchez JC. Blastocyst-endometrium interaction: intertwining a cytokine network. Braz J Med Biol Res. 2006:39:1373-85.

24. Fischer C, Drillich M, Odau S, Heuwieser W, Einspanier R, Gabler C. Selected pro-inflammatory factor transcripts in bovine endometrial epithelial cells are regulated during the oestrous cycle and elevated in case of subclinical or clinical endometritis. Reprod Fertil Develop. 2010;22:818-29.

25. Gani MO, Amin MM, Alam MGS, Kayesh MEH, Karim MR, Samad MA, et al. Bacterial flora associated with repeat breeding and uterine infections in dairy cows. Bangl J Vet Med. 2008;6:79-86.

26. Lange-Consiglio A, Spelta C, Garlappi R, Luini M, Cremonesi F. Intramammary administration of platelet concentrate as an unconventional therapy in bovine mastitis: first clinical application. J Dairy Sci. 2014;97:1-8.

27. Zimmermann R, Arnold D, Strasser E, Ringwald J, Schlegel A, Wiltfang J, et al. Sample preparation technique and white cell content influence the detectable levels of growth factors in platelet concentrates. Vox Sang. 2003:85:283-9.

28. Mojica-Henshaw MP, Jacobson P, Morris J, Kelley L, Pierce J, Boye M, et al. Serum-converted platelet lysate can substitute for fetal bovine serum in human mesenchymal stromal cell cultures. Cytotherapy. 2013;15:1458e-68e.

29. Lange-Consiglio A, Maggio V, Pellegrino L, Cremonesi F. Equine bone marrow mesenchymal or amniotic epithelial stem cells as feeder in a model for the in vitro culture of bovine embryos. Zygote. 2012;20:45-51.

30. Turner HE, Nagy ZS, Esiri MM, Wass JAH. The enhanced peroxidase one step method increases sensitivity for detection of Ki-67 in pituitary tumours. Clin Pathol. 1999;52:624-6.

31. Weibrich G, Kleis WK, Hitzle WE, Hafner G. Comparison of the platelet concentrate collection system with the plasma-rich-in growth factors kit to produce platelet rich plasma: a technical report. Int J Oral Max Imp. 2005;29:118-23. 
32. Rindermann G, Cislakova M, Arndt G, Carstanjen B. Autologous conditioned plasma as therapy of tendon and ligament lesions in seven horses. J Vet Sci. 2010;11:173-5.

33. Fresno L, Fondevila D, Bambo O, Chacaltana A, García F, Andaluz A. Effects of platelet-rich plasma on intestinal wound healing in pigs. Vet J. 2010;185:322-7.

34. Kim JH, Park C, Park HM. Curative effect of autologous platelet-rich plasma on a large cutaneous lesion in a dog. Vet Dermatol. 2009;20:123-6.

35. Thibodeaux JK, Del Vecchio RP, Broussard JR, Dickey JF, Hansel W. Stimulation of development of in vitro-matured and in vitro-fertilized bovine embryos by platelets. J Anim Sci. 1993;71:1910-6.

36. Siess W. Molecular mechanisms of platelet activation. Physiol Rev. 1989;69:58-168.

37. Whal SM, McCartney-Francis N, Mergenhager SE. Inflammatory and immunomodulatory roles of TGF- $\beta$. Immunol Today. 1989;10:258-61.

38. Larson $\mathrm{RC}$, Ignotz GG, Currie WB. Transforming growth factor and basic fibroblast growth factor synergistically promote early bovine embryo development during the fourth cell cycle. Mol Reprod Develop. 1992:33:432-5

39. Larson RC, Ignotz GG, Currie WB. Platelet derived growth factor (PDGF) stimulates development of bovine embryos during the fourth cell cycle. Development. 1992;115:821-6.

40. Munson L, Wilkinson JE, Bechtel M. Transforming growth factor-6 (TGF-(3) and platelet-derived growth factor (PDGF) are synergistic mitogens for bovine trophoblastic and endometrial epithelial cells. Biol Reprod. 1992;46 Suppl 1:S67

41. Kliman HJ, Feinberg RF, Haimowitz JE. Human trophoblast-endometrial interactions in an in vitro suspension culture system. Placenta. 1990;11:349-67.

42. Larson RC, Ignotz GG, Currie WB. Effect of fibronectin on early embryos development in cows. J Reprod Fertil. 1992;96:289-97.

43. Brown DC, Gatter KC. Monoclonal antibody Ki-67: its use in histopathology. Histopathology. 1990;17:489-503.

44. McCormick D, Chong H, Hobbs C, Datta C, Hall PA. Detection of the Ki-67 in fixed and wax embedded sections with the monoclonal antibody MIB1. Histopathology. 1993;22:355-60

45. Sasaki K, Murakami T, Kavasaki M, Takahasashi M. The cell cycle associated change of the Ki-67 reactive nuclear antigen expression. J Cell Physiol. 1987:133:579-84

46. Gustafsson $\mathrm{H}$, Emanuelson U. Has a repeat breeder cow in the present lactation a higher risk to become a repeat breeder in the next lactation? Proceding of the 14th international congress on animal reproduction, vol. 15:26. Sweden: Stockholm; 2000. p. 100.

47. King SG, Dobson H, Royal MD, Christley RM, Murray RD, Routly JE, et al. Identification of inadequate maternal progesterone concentrations in nulliparous dairy heifers and treatment with human chorionic gonadotrophin. Vet Rec. 2013;173:450-7.

48. Burton GJ, Watson AL, Hempstock J, Skepper JN, Jauniaux E. Uterine glands provide histiotrophic nutrition for the human fetus during the first trimester of pregnancy. J Clin Endocrinol Metab. 2002:87:2954-9.

49. Katagiri S, Takahashi Y. Changes in EGF concentrations during estrous cycle in bovine endometrium and their alterations in repeat breeder cows. Theriogenology. 2004;62:103-12.

\section{Submit your next manuscript to BioMed Central and take full advantage of:}

- Convenient online submission

- Thorough peer review

- No space constraints or color figure charges

- Immediate publication on acceptance

- Inclusion in PubMed, CAS, Scopus and Google Scholar

- Research which is freely available for redistribution

Submit your manuscript at www.biomedcentral.com/submit 